Type of the Paper (Article)

\title{
Prevalence of smokeless tobacco use in India and its association with occupations: A LASI study Bhavna Bharati ${ }^{1}$, Kirti Sundar Sahu ${ }^{1}$ and Sanghamitra Pati ${ }^{2 *}$ \\ 1 Public Health researcher, Bhubaneswar Advanced Rehabilitation Center 1; bhavnaotist@gmail.com \\ 2 Director, Indian Council of Medical Research, Regional Medical Research Centre, Bhubaneswar 2; drsang- hamitra12@gmail.com \\ * Correspondence drsanghamitra12@gmail.com
}

Background More than two-thirds of death in developing countries are due to non-communicable diseases (NCDs), and tobacco is a leading risk factor. Among different socio-demographic factors, occupation and its corelates have impact on use of smokeless tobacco (SLT) and the evidence in India is limited. The objectives of this study are to find out the overall prevalence of SLT use and its pattern of association with various occupation and associated variables. Methods: This study used data from Longitudinal Ageing Study in India (LASI) wave 1. Current and ever users of SLT are taken into consideration as target population. For the data analysis, survey-weighted tools have been applied for descriptive statistics and multivariable logistic regression model. The weighted data analysis has been done using R. Results and Discussion: From the sample size of $65561,38 \%$ have ever used either smoking or SLT, of them, $40 \%$ use tobacco in smoke form, $51 \%$ use SLT and $9 \%$ take both. At the population level, $22.8 \%$ and $20.4 \%$ are ever and current users of SLT respectively. Type, place, and workload in the occupation found to be significantly associated with SLT use. Workplace tobacco-cessation-policy for informal-workers is required to manage this issue.

Keywords: Smokeless tobacco, India, Ageing, Occupation, Tobacco consumption, LASI

\section{Introduction}

Worldwide, consumption of smoked and Smoke Less Tobacco (SLT) is a considerable threat to public health, leading to eight million deaths every year and is in the priority list of many countries [1,2]. More than two-third of the death in developing countries are due to non-communicable diseases (NCDs), and consumption of tobacco is a leading risk factor [1]. Despite several global policy measures, the trend is not reversing, and is estimated that by 2030 , ten million premature death is expected due to tobacco use per year. Only developing countries contribute to nearly $70 \%$ of this problem [3, 4]. Among the risk factors of NCDs, tobacco consumption is a preventable one [4, 5]. In global tobacco production, India ranks third and consumes around half of its production [6]. Globally, Global Adult Tobacco Survey (GATS 2016-2017) monitors and tracks tobacco use (smoking and smokeless). GATS is a nationalized survey using a standardized protocol in different countries, including India [7]. According to GATS nearly $30 \%$ of Indian adults use tobacco [8]. The prevalence of tobacco consumption in all forms is risen in developing countries, including India [9, 10]. About 20 million adults $(21.4 \%$ overall, $29.6 \%$ men and $12.8 \%$ women) regularly consume some of the other types of SLT [7]. The prevalence of smokeless tobacco use (21.4\%) is twice that of smoking (10.7\%) [7]. The use of SLT is prevalent not only among men, also in other vulnerable groups like teenagers, children, and women of reproductive age [11].

Tobacco is one of the most readily legally available, and accessible substance primarily contributing to death, suffering and being one of the major causes of various NCDs [12]. Chillum, cigars, cheroots, chuttas, hookah, and pipes are different types of smoking forms of tobacco in different parts of India. More than 40 types of SLT like paan, paan masala, khaini, zarda, mawa, gutka and mishri and gudakhu are used in chewing, snuffing and applying in teeth and gums [12,13]. Out of them, the mostly used SLT products in India are khaini (tobacco-lime mixture) used by more than ten percent, gutka (mixture of tobacco, lime and areca nut) used by nearly seven percent adults, betel 
quid with tobacco are used by six percent of adults and mishri, gul, gudakhu by nearly four percent for oral application [7]. SLT is wrongly perceived as safer than smoking which leads to higher consumption [13, 14], and initiation and persistence [13]. It is seen that tobacco use mainly starts in adolescence, whatever form it may be[11]. Moreover, chewing betel vine with aqueous calcium hydroxide paste (salked lime) with a nut commonly called supari and some spices, was in the culture and social life for million years, maybe from prehistoric times [11]. Consumption of tobacco is not restricted to individuals' behavior, rather than it is a complex process influenced by a variety of factors including social, environmental, psychological, and genetic factors. At individual-level, the determinants include gender, wealth index, caste, parental-use, peer-use, impact of advertisement, education, and place of stay [13]. A research study from India in 2016 shows, education and occupation as two important critical predictors of use of SLT [15].

The Global Framework Convention for Tobacco Control by the World Health Organization (WHO) in 2003 accelerated the regulation system and there is a global effort to reduce SLT use [16]. As a signatory country, India leads in these preventive measures by taking policy-level decisions. There has always been an effort by the state and central Governments at various policy levels to reduce tobacco use. Laws like, Products Prohibition of Advertisement and Regulation of Trade and Commerce, Production, Supply and Distribution Act, 2003 Cigarettes and other tobacco products act COTPA [4, 6, 17, 18] are enforced. Taxation or increasing the price of SLT products is one of the leading steps [13, 19]. Packaging showing the warning of adverse effects in the form of pictures and notes, which states "it is injurious to health" [6, 19]. Despite several measures taken by the Government, still understand the complexity of use of tobacco is a grey area for the scientific community.

As for the first time, the LASI was conducted in India as a part of the global study, with one of the components to understand tobacco use which is an essential aspect for many policy levels changes and health care facilities [17]. Though occupation plays a pivotal role in initiation and continuation of SLT, there is limited evidence available from India. To bridge this evidence gap, this study aims to understand the impact of different types and places of occupation on the use of smokeless tobacco. The objectives of this study are to find out 1) the overall prevalence of smokeless tobacco use (both ever and current user), 2) to understand the use of smokeless tobacco with variation in demographic variables, 3 ) the pattern of association of smokeless tobacco use with various occupation and related variables. 5) Impact of childhood adversity on the initiation and use of smokeless tobacco.

\section{Materials and Methods}

This is an exploratory study design using data from the first wave of Longitudinal Ageing Study in India (LASI), a nationally representative cross-sectional study [20]. The data was collected from all the states and union Territories across India in 2017-2018. A total number of 72,250 individuals participated in this study from more than 61,000 households. For the next 25 years, LASI will be conducted every two years. It is India's first ageing study where data was collected from individuals 45 and above and their spouses regardless of their age. The sampling and recruitment strategy details have been described elsewhere[20]. Data are collected in broad categories in household and individual interviews, physical measurements, and biomarkers. The LASI study was approved by the Indian Council of Medical Research (ICMR) Ethics Committee, and written informed consent was obtained from participants.

For this study, variables from the demographic, health behaviour, work-retirement, and pension modules from the "individual-questionnaire" were considered for analysis. From the demographic module, age, gender, caste, residence, education, religion, marital status, and wealth index are taken into consideration. From the health behavior module, specifically the smoking section of the individual-questionnaire are analyzed. We have considered both current- and ever-users of smokeless tobacco of any kind from 
the health behaviour module. Participants who ever smoked tobacco or used any kind of smokeless tobacco were separated from those who never used any tobacco product. From the population, users of any kind of tobacco (smoke or smokeless), only the SLT users are the target population for further analysis. There is a question asked, "what type of tobacco product have you used or consumed?" with a leading question to are "Do you consume any smokeless tobacco products such as chewing tobacco, gutka, or pan masala?" Their perception of childhood health status and the family financial status were asked from the childhood health module. From the work, retirement and pension module, their type of work "What is your occupation? Please specify?" are asked. The level of physical effort and working conditions are asked for the main job. The respondents graded their experience ranges from "all the time" to "almost never".

For this study, we have only included 45 years and above age group people. As this is a Nationalized survey with multistage sampling, weight has been assigned for each respondent based on multiple variables. To address true representativeness, weighted analysis has been done. Unit level data has been exported, cleaned and analyzed using $\mathrm{R}$ studio with R-software version 4 with the "weights" package [21]. For multivariate analysis, regrouping of the occupation has been done as follows. Occupation category- 1 includes "Legislators, senior officials, and Managers", "Professionals" and "Technicians and associate professionals and Clerks". Category-2 includes "Service workers and shop and markets sales workers", "Skilled agricultural and fishery workers", "Craft and related trade workers", and "Plant and machine operators and assemblers". Category-3 includes "Elementary Occupations", "Workers not classified anywhere" and "Others".

\section{Results}

A total number of 72,250 individuals participated in this study. As LASI mainly focuses on data collection from $45+$ age populations, six percent of the population comes under the 18 to 44 age group; we excluded that group from analysis, as they are not from the representative sample. Nearly $49 \%$ of the participants are within the 45 to 60 age group, and $45 \%$ are from the $60+$ age group. The sample size for this study is 65561 (45 years+). Among them, 24777 (38\%) have ever used either smoking or SLT. When analyzed for the type of tobacco product use, $39.8 \%$ use tobacco in smoke form, $51.3 \%$ use SLT and $8.9 \%$ both SLT and smoke tobacco. We included population using SLT and both smoke and SLT for our analysis. At the population-level, $14090(22.8 \%)$ and $12461(20.4 \%)$ are ever users and current users of SLT respectively. In SLT users $88.6 \%$ continue using SLT with a quit proportion of $11.4 \%$. All the analysis has been performed between ever and current users of SLT to understand the user and quitters' behaviour.

Table 1 describes the demographic distribution of SLT users. Among current and ever SLT users, the proportion of 60+ age group, male, rural and poor economic status are more than their respective counterparts. The share of elderly populations is more than the younger population. With respect to gender, males are consuming more SLT compared to females. Among the four categories of castes, schedule tribes (ST) population are the maximum consumers, with a share of $31.6 \%$ in ever used and $28.4 \%$ among current users of SLT. In contrast, other backward classes $(\mathrm{OBC})$ and general categories are the least users of SLT in both the cases. 
Table 1 Demographic variables and their association with current and ever smokeless tobacco users.

\begin{tabular}{|c|c|c|c|c|c|}
\hline \multirow[t]{2}{*}{ Features } & \multirow[t]{2}{*}{ Categories } & \multicolumn{2}{|c|}{ Ever users } & \multicolumn{2}{|c|}{ Current user } \\
\hline & & $\mathrm{N}$ & $\%$ & $\mathrm{~N}$ & $\%$ \\
\hline \multirow[t]{2}{*}{ Age } & $45-59$ years & 7097 & 21.4 & 6465 & 19.6 \\
\hline & $60+$ years & 6993 & 24.3 & 5996 & 21.3 \\
\hline \multirow[t]{2}{*}{ Gender } & Male & 8485 & 31.0 & 7425 & 27.5 \\
\hline & Female & 5605 & 16.0 & 5036 & 14.4 \\
\hline \multirow[t]{4}{*}{ Caste } & Scheduled Caste & 2574 & 26.2 & 2340 & 23.7 \\
\hline & Scheduled Tribe & 3214 & 31.6 & 2761 & 28.4 \\
\hline & Other Backward Class & 5030 & 20.8 & 4508 & 18.5 \\
\hline & General & 2771 & 20.9 & 2407 & 18.4 \\
\hline \multirow[t]{2}{*}{ Residence } & Rural & 10582 & 26.5 & 9459 & 23.8 \\
\hline & Urban & 3508 & 14.9 & 3002 & 13.0 \\
\hline \multirow[t]{5}{*}{ Wealth index } & Poorest & 3274 & 26.1 & 2966 & 23.5 \\
\hline & Poorer & 3213 & 26.1 & 2911 & 23.7 \\
\hline & Middle & 2822 & 22.8 & 2504 & 20.3 \\
\hline & Richer & 2639 & 21.9 & 2297 & 19.5 \\
\hline & richest & 2142 & 16.5 & 1783 & 14.2 \\
\hline \multirow[t]{4}{*}{ Education } & No school & 6810 & 23.3 & 6143 & 21.2 \\
\hline & Less than 5 years & 2080 & 28.2 & 1838 & 25.2 \\
\hline & 5 to 9 years & 3334 & 24.9 & 2898 & 21.8 \\
\hline & $10+$ years & 1866 & 16.0 & 1582 & 13.8 \\
\hline \multirow[t]{3}{*}{ Marriage } & Currently married & 10522 & 23.1 & 9339 & 20.8 \\
\hline & Widow & 3169 & 22.5 & 2758 & 19.7 \\
\hline & Other & 398 & 18.6 & 363 & 16.5 \\
\hline \multirow[t]{4}{*}{ Religion } & Hindu & 10563 & 23.3 & 9460 & 20.8 \\
\hline & Muslim & 1740 & 23.5 & 1567 & 21.4 \\
\hline & Christian & 1332 & 16.4 & 1057 & 12.3 \\
\hline & Others & 455 & 16.7 & 377 & 14.6 \\
\hline
\end{tabular}

Place of residence also influences the use of SLT, as an urban population are fewer consumers than rural counterpart. The economic status determines the SLT use by poor and poorest being the maximum users than middle and richer communities. In terms of education, people with 10+ years of education are the least users of SLT compared to other categories of education, and there is a one percent difference between no-schooling and 5 to 9 years of schooling. There is a minimal difference in SLT consumption in currently married and widowed. Stratifying the users based on religion shows, Hindus and Muslims are the maximum consumers of SLT than Christians and others. The quitting pattern can be explored by comparing the difference between ever and current users of SLT. The main findings of quitting pattern are, in the age group of $45-59$ years, $2 \%$ of the population quit SLT while in 60+ the share is 3\%. The quitting habit is increasing with the increase in age. The quitting rate of schedule caste and schedule tribe is around $3 \%$ in caste, while other backward classes and general are $2 \%$. There is no difference seen in the quitting pattern between rural and urban with quitting percentage of around 3\%. The quitting pattern among the four-education level shows that less than five years and 5 to 9 years of schooling have a $1 \%$ more quitting rate than $10+$ years and no schooling. 
Figure 1 Childhood health, financial status and its association with smokeless tobacco



n current user \% aver users \%

There may be childhood adversities that impact the initiation and consumption of smokeless tobacco. Two childhood features are considered, namely, "childhood health" and "family status in terms of finance, from birth to age 16". Family status is one of the most critical components that determine the use and the continuity of use of SLT. To find out the association between SLT use with childhood characteristics, further analysis is done and described below in Figure 1. In "ever-users," both the extreme categories of childhood health have a similar percentage of SLT use ( $24 \%)$. In terms of very good childhood health, the quitting pattern is $2.4 \%$, while in contrast, the very poor category has no quitting pattern. Family status in terms of finance, poor and varied financial status is almost similar in terms of SLT use, around 30\% and $27 \%$ in ever and current use, respectively. It has been seen that there is no notable change in quitting pattern of SLT across the family status.

Besides demography and family status, occupation and its correlates contribute to the use of SLT. Table 2 explains the association of type, place, kind of business and type of employer with SLT and figure 2 illustrates the impact of the level of stress in the work area. The analysis has been stratified between current and past workers for current users of SLT to understand the impact of work-related stress on the use of SLT. Table 2 focuses on occupational significance for SLT users in a broader aspect. We can see in types of occupation; skilled agricultural and fishery workers are the maximum consumers of SLT in both current and past workers. Among past workers, plant and machine operators share the same percentage with agricultural and fishery workers (22\%). Professionals are the least consumers of SLT in both current and past workers, nearly $10 \%$. In legislators, senior officials, and managers for current workers, the share is nearly $9 \%$, increasing to $17 \%$ for past workers. In the case of agricultural workers, the use of SLT is higher for current users and decreased by $7 \%$ points for past users.

Regarding the place of occupation, for current workers, people working without a fixed location have the highest share with $31.3 \%$, followed by $28.5 \%$ for own farm or business. In contrast, for past workers, people working with fixed locations outnumber other categories, $23.4 \%$. Across all categories, SLT use for past workers is less than the current workers. 
Table 2 Impact of Occupational on smokeless tobacco use for current users

\begin{tabular}{|c|c|c|c|c|}
\hline \multirow[t]{2}{*}{ Categories } & \multicolumn{2}{|c|}{ Current workers } & \multicolumn{2}{|c|}{ Past workers } \\
\hline & $\mathrm{N}$ & $\%$ & $\mathrm{~N}$ & $\%$ \\
\hline \multicolumn{5}{|c|}{ Type of Occupation } \\
\hline Legislators, senior officials, and Managers & 25 & 8.97 & 42 & 17.2 \\
\hline Professionals & 166 & 9.88 & 96 & 9.89 \\
\hline Technicians and associate professionals & 88 & 13.3 & 62 & 12.6 \\
\hline Clerks & 84 & 19.5 & 87 & 21.3 \\
\hline Service workers and shop and markets sales workers & 648 & 21.3 & 209 & 18.2 \\
\hline Skilled agricultural and fishery workers & 3683 & 29.3 & 1404 & 22.0 \\
\hline Craft and related trade workers & 217 & 17.6 & 100 & 16.6 \\
\hline Plant and machine operators and assemblers & 205 & 22.7 & 131 & 22.0 \\
\hline Elementary Occupations & 1464 & 26.1 & 593 & 20.9 \\
\hline Workers not-classified any where & 829 & 26.2 & 391 & 21.4 \\
\hline Others & 222 & 21.0 & 13 & 7.01 \\
\hline \multicolumn{5}{|l|}{ Place of work } \\
\hline Own dwelling & 898 & 21.7 & 388 & 15.1 \\
\hline Own farm or business & 2603 & 28.7 & 123 & 18.8 \\
\hline Employer's dwelling & 249 & 25.3 & 647 & 19.0 \\
\hline Employer's workplace & 791 & 21.5 & 111 & 19.6 \\
\hline Construction site & 188 & 20.0 & 301 & 19.2 \\
\hline Place with fixed location & 1312 & 19.4 & 401 & 23.4 \\
\hline Place without fixed location & 1552 & 31.3 & 1148 & 22.4 \\
\hline Other, please specify & 43 & 19.6 & 14 & 17.6 \\
\hline \multicolumn{5}{|c|}{ Kind of business } \\
\hline Agriculture, forestry, and fishing & 4542 & 28.2 & 1861 & 21.9 \\
\hline Mining and quarrying & 113 & 27.7 & 86 & 27.4 \\
\hline Manufacturing & 299 & 22.9 & 141 & 17.8 \\
\hline Electricity, gas, steam, or air conditioning supply & 49 & 23.7 & 29 & 16.4 \\
\hline Water supply: sewerage, waste management & 66 & 28.4 & 36 & 26.5 \\
\hline Construction & 484 & 27.3 & 139 & 17.9 \\
\hline Wholesale and retail trade & 617 & 22.8 & 167 & 19.6 \\
\hline Transportation and storage & 208 & 25.2 & 60 & 15.7 \\
\hline Accommodation and food service activities & 161 & 22.0 & 65 & 18.3 \\
\hline Information and communication & 19 & 10.4 & 16 & 14.5 \\
\hline Financial and insurance activities & 11 & 4.3 & 7 & 7.5 \\
\hline Real estate activities & 26 & 24.5 & 12 & 27.5 \\
\hline Professional, scientific, and technical activities & 56 & 14.2 & 37 & 8.5 \\
\hline Administrative and support service activities & 81 & 13.4 & 55 & 17.3 \\
\hline Public administration and defense & 55 & 10.9 & 58 & 14.7 \\
\hline Education & 128 & 11.1 & 87 & 13.3 \\
\hline Human health and social work activities & 76 & 17.8 & 32 & 16.5 \\
\hline Art, entertainment, and recreation & 70 & 19.8 & 32 & 23.6 \\
\hline Other service activities & 353 & 28.8 & 125 & 24.3 \\
\hline Activities of households as employers: & 143 & 18.5 & 65 & 22.1 \\
\hline Activities of extraterritorial organizations and bodies & 10 & 26.6 & 8 & 16.1 \\
\hline Other & 69 & 18.5 & 12 & 16.5 \\
\hline \multicolumn{5}{|c|}{ Type of employer\# } \\
\hline Government sector & 464 & 16.2 & 384 & 15.7 \\
\hline Private sector /organization /entrepreneur & 881 & 21.7 & 640 & 21.6 \\
\hline Cooperatives & 27 & 23.5 & 25 & 23.0 \\
\hline NGO/Trust & 78 & 30.9 & 59 & 23.3 \\
\hline
\end{tabular}




\begin{tabular}{rrrrrr}
\hline Individual household & 363 & 23.2 & 481 & 23.7 \\
Other, please specify & 84 & 21.4 & 165 & 18.9 \\
\hline
\end{tabular}

\# Only for wage/salaried workers

When analyzed for kind of business for current workers, use of SLT is less for financial and insurance activities, public administration and defense, education, information, and communication. In contrast, it is high for agriculture, forestry, fishing, water supply, household employee, construction, and mining workers. For past workers, the pattern is nearly the same except for agricultural workers. In relation to the type of employer for current workers, people working in NGO and trust have the highest share (31\%), whereas the share is lowest for people working in the government sector $(16 \%)$. For past workers government sector has the least share, whereas all other categories have a similar share for SLT use.

Figure 2 Physical effort and working condition required in a) current \& b) past job for current SLT users.
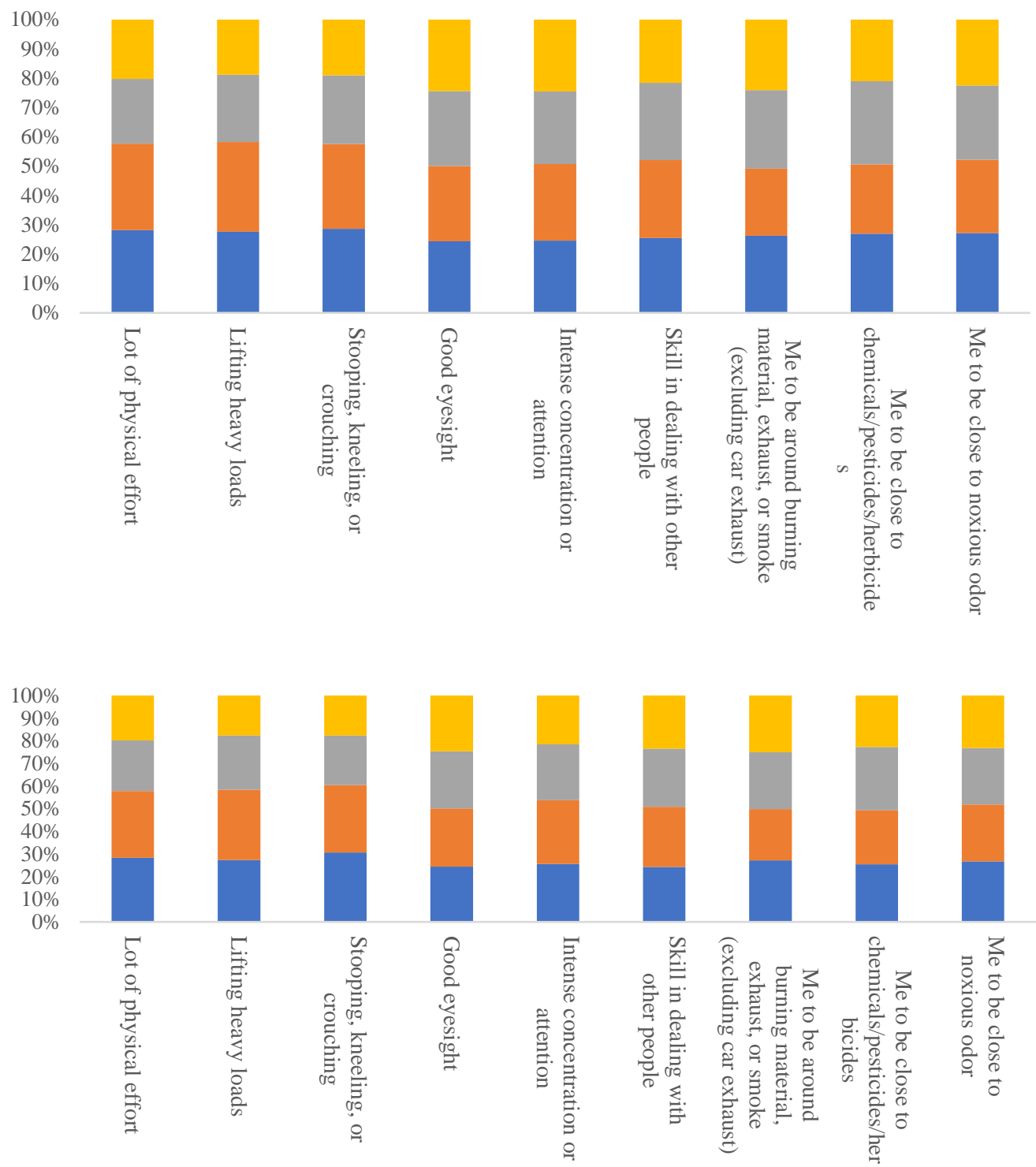
Table 3 Multivariate logistic regression analysis for current use of smokeless tobacco and occupation with other covariates.

\begin{tabular}{|c|c|c|}
\hline & Unadjusted odds ratio & Adjusted odds ratio \\
\hline \multicolumn{3}{|l|}{ Occupation } \\
\hline Category-1 & Ref & Ref \\
\hline Category-2 & $2.6(1.9-3.6)^{* * *}$ & $1.4(1-1.9)^{* * *}$ \\
\hline Category-3 & $2.9(2.1-4)^{* * *}$ & $1.6(1.2-2.1)^{* * *}$ \\
\hline Category-4 & $1.4(1-1.9)^{* * *}$ & $1.1(0.8-1.5)$ \\
\hline \multicolumn{3}{|l|}{ Age } \\
\hline $45-59$ & & Ref \\
\hline $60+$ & & $1.1(1-1.2)^{* * *}$ \\
\hline \multicolumn{3}{|l|}{ Gender } \\
\hline Female & & Ref \\
\hline Male & & $2.2(2-2.4)^{* * *}$ \\
\hline \multicolumn{3}{|l|}{ Income } \\
\hline Richest & & Ref \\
\hline Richer & & $1.3(1.2-1.5)^{* * *}$ \\
\hline Middle & & $1.4(1.2-1.5)^{* * *}$ \\
\hline Poorer & & $1.6(1.4-1.8)^{* * *}$ \\
\hline Poorest & & $1.5(1.4-1.7)^{* * *}$ \\
\hline \multicolumn{3}{|l|}{ Education } \\
\hline $10+$ years & & Ref \\
\hline 5 to 9 years & & $1.4(1.2-1.6)^{* * *}$ \\
\hline Less than 5 years & & $1.5(1.3-1.7)^{* * *}$ \\
\hline No school & & $1.4(1.3-1.6)^{* * *}$ \\
\hline \multicolumn{3}{|l|}{ Residence } \\
\hline Urban & & Ref \\
\hline Rural & & $1.6(1.5-1.8)^{* * *}$ \\
\hline \multicolumn{3}{|l|}{ Caste } \\
\hline General & & Ref \\
\hline Schedule caste & & $1(0.9-1.1)$ \\
\hline Schedule tribe & & $1.2(1-1.3)^{*}$ \\
\hline Other backward class & & $0.9(0.8-0.9)^{* * *}$ \\
\hline \multicolumn{3}{|l|}{ Employer } \\
\hline Non-government & & Ref \\
\hline Government & & $1(0.9-1)$ \\
\hline \multicolumn{3}{|l|}{ Childhood health } \\
\hline Very good & & Ref \\
\hline Good & & $0.9(0.9-1)$ \\
\hline Poor & & $0.8(0.6-0.9) *$ \\
\hline \multicolumn{3}{|l|}{ Childhood finance } \\
\hline Pretty well off & & Ref \\
\hline Average & & $1(0.8-1.1)$ \\
\hline Poor & & $1.6(1.4-1.8)^{* * *}$ \\
\hline
\end{tabular}

The demand for occupation plays a significant role in SLT use. When considering physical effort in current workers, those who make much physical effort all the time have nearly the same use of SLT, and the same pattern is seen in past workers. With the intensity of physical effort, the use of SLT also increases. Most of the time, those who lift heavy loads are the maximum consumers of SLT in both current and past workers, with $31 \%$ and $24 \%$, respectively. Those working with chemicals sometimes are the leading consumers of SLT (31\%) in current workers, and the same pattern is also seen for the past workers (23.6\%). Figure 2 shows no remarkable difference in the percentage of SLT 
use in current and past workers across the dedication of time of work required and requirement of eyesight.

The multivariate logistic regression analysis has been performed to understand the association of occupation on smokeless tobacco use after adjusting for age, gender, education, economic condition, place of residence, caste, type of employer, childhood financial status and childhood health. The result of the model, as shown in table 3 summarizes there is a statistically significant role of occupation on the use of SLT for current users even after adjusting with socio-demographic features and other variables. Adjusted and unadjusted Odds ratio for occupation has been mentioned in the table 3 .

\section{Discussion}

The use of smokeless tobacco has several direct and indirect impacts on different dimensions of life. Occupation has a strong association with using smokeless tobacco products. India, with an agriculture-dominated society, has a vast share of the user of smokeless tobacco. With a sample size of 65561 (45 years and above age group only), this study tried to explore the pattern of uses of smokeless tobacco products in relation to occupation, demographic characteristics, and childhood adversities in India year 2018. Our result shows, nearly $38 \%$ of the adult population $(45+)$ have ever used either smoking or SLT for the year 2018, which is almost 10\% more compared to the Global Adult Tobacco Survey of India 2 (GATS-2) shows $28 \%$ 2016-17. At the population level, 20.4\% are current users of SLT which is nearly similar to the proportion of $21.4 \%$ by GATS-2 [22] .

The findings from our study for the demographic distribution of SLT users are at par with the findings from GATS-2, representing the robustness of SLT user's data across the nation. The typical characteristics of SLT users are $60+$ population, male, rural and poor wealth index. Elderly populations are more SLT users than the younger population by $2 \%$, which is a matter of concern as elderly populations are more prone to other chronic health conditions, including cancer. With regards to gender, the share of males is almost double than females in terms of SLT consumption in India the cause of this inequality may be associated with employment status as in India $71 \%$ of the male are employed compared to 22\% females as per "periodic labor force survey" for 2017-18 by Ministry of Statistics and Program Implementation (MOSPI) [23]. Among the four categories of castes, schedule tribe are maximum consumers of SLT with $28.4 \%$, followed by schedule caste with $24 \%$, and a similar pattern can be observed in wealth index with nearly $23 \%$ from both poorer and poorest categories. In terms of place of residence, the rural population share the same percentage respectively (23\%). As we know, smokeless tobacco use leads to both health and non-health complications; high use of smokeless tobacco among socio-economically backward populations poses a threat to their self, family, and community. With this background, understanding of the initiation of use of SLT as well as continuation has been explored as mentioned below.

Initiation of use of any tobacco product assumed to be associated with childhood adversities, including health, finance, and socioeconomic characteristics. In our study, childhood health and family status are taken into consideration from birth to age 16. Our findings suggest that both parameters have a significant influence on the use of SLT. In later life people with better health and financial status have higher quitting pattern than with low economic status. despite the understanding of the use of SLT can deteriorate their existing poor health condition, the negligible quitting pattern is a matter of concern for the healthcare system and society. Once imitated, SLT use continuation might be associated with occupation and its correlates and other associated factors.

When analyzed for the association between use of SLT and occupation, it is found that the type of occupation, place, type of work, kind of business, type of employer, and the level of stress within the occupation has a crucial role, as evidenced in the past literature 
$[15,24,25]$. Skilled agricultural and fishery workers have the highest share of SLT while professionals, legislators, senior officials, and managers are the least consumers of SLT. The reason behind this variation can be partly explained through social status, role model attitude and peer environment. When all the members are a user of SLT, there is not much difference for a growing child to get used to tobacco as for him it is not something unusual or harmful. Similarly, people with designated jobs are more conscious of their designation to use SLT in public rather than people working in farming land whose socioeconomic status is poor [26].

Along with the type of occupation, workplace also determines the use of SLT as people working in "no fixed organization" or place and type of work; for example, daily wage laborer has the highest share among SLT users compared to people working with "fixedlocations". Similarly, "kind of business" also impacts the use of SLT for example, as our finding shows financial and insurance activities, public administration and defense, education, information, and communication business workers use limited tobacco products compared to agriculture, forestry, fishing, water supply, household employee, construction, and mining workers. For example, individuals working with insurance companies deal more with unnatural death like accidents and chronic diseases, and tobacco use is one of India's leading causes of mortality and morbidity. This can be the reason behind the less use of tobacco by people working in insurance sectors. It may be due to their high health literacy and knowledge of the consequences of tobacco products [27].

People working with insurance sectors are more aware of the side effects of tobacco use as they are more health literate. As a developing economy, India has a mixed culture of type of employer where a high share of private, NGO and trust as an employer compared to a public entity (Govt.). Work environment varies from corporate type setup to primary grassroots type of work like working in agricultural land or daily wage laborer. As our result shows, people working in NGOs and trust have the highest share of SLT use; in contrast, the share is lowest for people working in the government sector. The crucial role of NGOs in India is to uplift the overall status of vulnerable populations in terms of health, economy, and education. All these require intensive work in hard-toreach areas, urban slums, working with the homeless population, where the psychological status of the worker might not be good. SLT has also been associated with the type of physical and mental stress a personal experience during his work schedule. Those who make much physical effort all or most of the time have high prevalent SLT use; for example, those who lift heavy loads, working with chemicals and work with maximum eyesight requirements are the maximum consumers.

Multivariate logistic regression analysis shows compared to higher-level occupation; other groups were significantly at higher risk for the use of SLT. The role of gender seems to be extremely high even after adjusting with other variables, i.e., an odds ratio of 2.2 for males. Similarly, economic status, education, and residence place have a significant role in determining the use of SLT. Interestingly type of employer has no role, and the reason behind it might be due to the implementation of the anti-tobacco policy in the Government workplace. Poor childhood financial status might have a significant role in initiating and continue the use of SLT.

\section{Implication for workplace policy and healthy work environment}

Central, as well as State governments, have formulated anti-tobacco policies to curb the use of smoking as well as SLT in the workplace since 2008. Our result reflects occupation, and its covariates have a strong association with the use of SLT, as evidenced in the previous literature. Informal workers without a fixed location have no tobacco policy in place, resulting in no difference in SLT intake. A deaddiction and quitting policy targeting rural male informal workers should be the focus of the Government. 


\section{Limitation of the study}

The limitation of this study is the response related to occupation and its correlates and the use of SLT, which are self-reported and not validated with external sources. As the primary goal of LASI is to collect information from the geriatric/elderly population, the result cannot be generalized for the whole adult population. While using this result for policymaking, GATS result should be used to compare and complement the findings.5.

\section{Conclusions}

SLT use is a significant public health issue, and this study shows that a huge share of population uses SLT in any form. Several Government policies and effort seems to be there in place, still ineffective to completely control the use of tobacco. It is interesting to see the variation in SLT use in different types of occupation. Moreover, the relationship of the condition in the workplace also determines the use of SLT use. Most of the time, workers who lift heavy loads are the maximum consumers of SLT. There should be policy-level changes focusing specifically on the workplace, which can be a boosting factor for the initiation of SLT.6. Patents

Author Contributions: Conceptualization, BB. and SP.; methodology, BB and KS.; formal analysis, $\mathrm{BB}$ and KS.; resources, $\mathrm{BB}$. and SP.; data curation, $\mathrm{BB}$ and KS; writing - original draft preparation, $\mathrm{BB}$ and KS.; writing - review and editing, SP.; visualization, BB and KS; supervision, SP.; funding acquisition, SP. All authors have read and agreed to the published version of the manuscript."

Funding: This research received no external funding

Institutional Review Board Statement: Not applicable

Informed Consent Statement: Not applicable

Data Availability Statement: In this section, please provide details regarding where data supporting reported results can be found, including links to publicly archived datasets analyzed or generated during the study. Please refer to suggested Data Availability Statements in section "MDPI Research Data Policies" at https://www.mdpi.com/ethics. You might choose to exclude this statement if the study did not report any data.

Acknowledgments: WE would like to thank IIPS team for the data collection for LASI and team ICMR-RMRC-Bhubaneswar for their support.

Conflicts of Interest: The authors declare no conflict of interest.

\section{References}

[1] World Health Organization. Global tobacco report, https:/www.who.int/teams/health-product-and-policystandards/assistive-and-medical-technology/health-promotion (2019, accessed 29 June 2021).

[2] Singh PK, Yadav A, Lal P, et al. Dual Burden of Smoked and Smokeless Tobacco Use in India, 2009-2017: A Repeated Cross-Sectional Analysis Based on Global Adult Tobacco Survey. Nicotine \& Tobacco Research 2020; 22: 2196-2202.

[3] Islam MS, Saif-Ur-Rahman KM, Bulbul MdMI, et al. Prevalence and factors associated with tobacco use among men in India: findings from a nationally representative data. Environ Health Prev Med 2020; 25: 62.

[4] Panda B, Rout A, Pati S, et al. Tobacco Control Law Enforcement and Compliance in Odisha, India Implications for Tobacco Control Policy and Practice. Asian Pacific journal of cancer prevention: APJCP 2012; 13: 4631-7.

[5] Pati S, Patnaik S, Swain S. 5A Tobacco Cessation Strategy and Physician's Practice in Odisha, India: A CrossSectional Study. Int J Prev Med 2014; 5: 325-332.

[6] Chandrupatla SG, Tavares M, Natto ZS. Tobacco Use and Effects of Professional Advice on Smoking Cessation among Youth in India. Asian Pac J Cancer Prev 2017; 18: 1861-1867. 
[7] World Health Organization. Global Adult Tobacco Survey India 2016-17, https://ntcp.nhp.gov.in/assets/document/surveys-reports-publications/Global-Adult-Tobacco-Survey-SecondRound-India-2016-2017.pdf (2019, accessed 12 August 2021).

[8] Singh A, Arora M, Bentley R, et al. Geographic variation in tobacco use in India: a population-based multilevel cross-sectional study. BMJ Open 2020; 10: e033178.

[9] Hussain MA, Pati S, Swain S, et al. Pattern and Trends of Cancer in Odisha, India: A Retrospective Study. Asian Pacific Journal of Cancer Prevention 2012; 13: 6333-6336.

[10] Pati S. Putting Tobacco Cessation and Prevention into Undergraduate Medical Education. Int J Prev Med 2014; 5: 69-75.

[11] Gupta PC, Ray CS. Smokeless tobacco and health in India and South Asia. Respirology 2003; 8: 419-431.

[12] Bhawna G. Burden of Smoked and Smokeless Tobacco Consumption in India - Results from the Global adult Tobacco Survey India (GATS-India)- 2009-2010. Asian Pacific Journal of Cancer Prevention 2013; 14: 3323-3329.

[13] Thakur JS, Paika R. Determinants of smokeless tobacco use in India. Indian J Med Res 2018; 148: 41-45.

[14] John RM. Price Elasticity Estimates for Tobacco Products in India. Health Policy Plan 2008; 23: 200-209.

[15] Rawat R, Gouda J, Shekhar C. Smokeless tobacco use among adult males in India and selected states: Assessment of education and occupation linkages. Journal of Human Behavior in the Social Environment 2016; 26: 236-246.

[16] WHO. WHO framework convention on tobacco control. Geneva: WHO, 2005.

[17] Yadav A, Singh PK, Yadav N, et al. Smokeless tobacco control in India: policy review and lessons for highburden countries. BMJ Glob Health 2020; 5: e002367.

[18] Pradhan A, Oswal K, Padhan A, et al. Cigarettes and Other Tobacco Products Act (COTPA) implementation in education institutions in India: A crosssectional study. Tob Prev Cessat 2020; 6: 51.

[19] John RM. Price Elasticity Estimates for Tobacco Products in India. Health Policy Plan 2008; 23: 200-209.

[20] International Institute for Population Sciences (IIPS), NPHCE, MoHFW, Harvard T. H. Chan School of Public Health (HSPH) and the University of, Southern California (USC). Longitudinal Ageing Study in India (LASI) Wave 1, 2017-18, India Report. International Institute for Population Sciences, Mumbai., https://www.iipsindia.ac.in/sites/default/files/LASI_India_Report_2020_compressed.pdf (2020).

[21] Pasek J, Schwemmle with some assistance from AT and some code modified from R -core; A contributions by GC and M. weights: Weighting and Weighted Statistics, https://CRAN.R-project.org/package=weights (2021, accessed 26 June 2021).

[22] Lahoti S, Dixit P. Declining trend of smoking and smokeless tobacco in India: A decomposition analysis. PLOS ONE 2021; 16: e0247226.

[23] Ministry of Statistics and Programme Implementation. Annual Report Periodic Labour Force Survey (PLFS) 2017-18, http://mospi.nic.in/sites/default/files/publication_reports/Annual\%20Report\%2C\%20PLFS\%20201718_31052019.pdf?download=1 (2019, accessed 21 July 2021).

[24] Prabhakar B, Narake SS, Pednekar MS. Social disparities in tobacco use in India: The roles of occupation, education and gender. Indian Journal of Cancer 2012; 49: 401.

[25] Thakur JS, Prinja S, Bhatnagar N, et al. Widespread inequalities in smoking \& smokeless tobacco consumption across wealth quintiles in States of India: Need for targeted interventions. Indian J Med Res 2015; 141: 789-798.

[26] Sorensen G, Pednekar M, Cordeira LS, et al. Effects of a Worksite Tobacco Control Intervention in India: The Mumbai Worksite Tobacco Control Study, a Cluster Randomized Trial. Tob Control 2017; 26: 210-216.

[27] Panda R, Mahapatra S, Gaurav K, et al. A quasi-experimental intervention to assess the effectiveness of a physician-delivered tobacco cessation intervention in India: A detailed study protocol. SAGE Open Medicine 2017; 5: 205031211769717. 
